\title{
Harun Tolasa'nın Osmanlı Edebiyatı Araştırmalarına Yaptığı Katkılar Üzerine*
}

\author{
An Assessment of Harun Tolasa's Contributions to Research on \\ Ottoman Literature
}

\section{Furkan ÖZTÜRK ${ }^{* *}$}

Özet: Bu makale, Harun Tolasa'nın genel çalışma alanları, özellikle üzerinde ısrarla durduğu konular hakkındadır. Divan tahlili, on altıncı yüzyıl tezkire dili ve üslubu, divan önsözleri ve otobiyografik metinler Tolasa'nın temel araştırma alanlarıdır. Vukufiyeti, titizliği ve model alınan eserleriyle Tolasa, Osmanlı edebiyatı çalışmalarında çok önemli bir bilim adamıdır.

Anahtar Sözcükler: Osmanlı Edebiyatı, eleştiri, tezkire, divan tahlili, önsöz, otobiyografi

Abstract: This article focuses upon the works of Harun Tolasa (1938-83), especially those topics that he pursued with persistence. Harun Tolasa's primary areas of research were divan analysis, sixteenth century tezkire language and diction, divan preambles and autobiographic documentation. In respect to knowledge, fastidiousness, and model research, Tolasa was a very important scholar of Ottoman literature.

Keywords: Ottoman Literature, tezkire, divan analysis, preamble, autobiography

Osmanlı edebiyatı araştırmalarına büyük katkılar yapmış ve erken yaşlarda aramızdan ayrılmış iki büyük bilim adamından biri Mehmet Çavuşoğlu (1936-1987), bir diğeri de Harun Tolasa (1938-1983)'dır. Bu bilim adamlarının akademik yaşamları ve yaptığı çalışmalara bakılırsa iki önemli ortak özellik hemen göze çarpmaktadır. Bunlardan ilki, aynı hocadan yani Ali Nihat Tarlan (1898-1978)' dan doktora yapmış olmaları, diğeri ise doktora tezlerinin divan tahlili çalışması olmasıdır. Mehmet Çavuşoğlu Necati Bey Divanı'nın, Harun Tolasa ise Ahmet Paşa Divanı'nın tahlilini yapmışlardır. Çavuşoğlu sonraki çalışmalarında daha çok eleştirel metin neşirleri üzerine yoğunlaşırken, Harun Tolasa on altıncı yüzyıl tezkirelerindeki dil, üslup ve edebiyat araştırması konuları üzerinde çalışmalar yürütmüştür.

Harun Tolasa'nın ilk önemli akademik çalışması olan “Ahmet Paşa Divanı'nın Tahlili ve Semantik İndeksi" adlı doktora tezi 1973 y1lında Ahmet Paşa'nın Şiir Dünyası adıyla yayımlanmıştır. Tolasa'nın bu kitabı o yıllar için özellikle adıyla dikkatleri üzerine çekmiştir. Bu çalışma, içerik ve yöntem bakımından divan tahlili çalışmalarının modeli kabul edilen Tarlan'ın Şeyhî Divanı'nı Tedkîk adlı kitabından sonra yayımlanmış ilk eserlerden biridir. Mehmet Çavuşoğlu'nun Necatî Bey Divanı'nın Tahlili ve sonraki yıllarda Amil Çelebioğlu (19341990)'nun doktora öğrencilerinden Cemal Kurnaz'ın Hayalı̂ Bey Divanı (Tahlili) ve Nejat Sefercioğlu'nun Nevî Divanı'nın Tahlili bu tür çalışmaların öncüleri olmaları yönüyle büyük

\footnotetext{
* Bu yazı, 16-18 Ekim 2009 tarihlerinde Mardin'de düzenlenen "V. Klâsik Türk Edebiyatı Sempozyumu'nda (Prof. Dr. Harun Tolasa Hatırasına)" sunulan bildirinin gözden geçirilmiş ve genişletilmiş biçimidir.

** Yrd. Doç. Dr., Akdeniz Üniversitesi, Edebiyat Fakültesi, Türk Dili ve Edebiyatı Bölümü, furkanozturk@akdeniz.edu.tr
} 
önem taşımaktadır. Son on yılda divan tahlili çalışmalarının Osmanlı Edebiyatı araştırmalarındaki yerleri ve işlevlerini değerlendiren üç bilimsel yazı yayımlanmıştır. Bu yazılardan ilki, Yekta Saraç'ın önce "tahlil" terimini irdeleyerek, bu çerçevede divan tahlili incelemelerinin "ne olduğu" ve "ne olması gerektiği" ile ilgili düşünce ve önerilerini tartıştığı yazısıdır (Saraç, 1999, 209-219). Sözü edilen makalede Saraç, Tarlan'ın Şeyhi Divanı'nı Tedkik'i ile sonra bu eseri model alarak yapılan divan tahlili çalışmalarını, Tarlan'ın eserini önceleyerek birbirinden ayırır. Yazıda Tarlan sonrası en çok Çavuşoğlu'nun divan tahlili modelinin takip edildiğini, söylediklerinin yapılan çalışmaların değerini ve Osmanlı Edebiyatı incelemelerine katkılarını inkâr olarak değerlendirilmemesi gerektiğini, bunun bir durum tespiti olarak kabul edilmesinin daha yerinde olacağını belirttikten sonra şunları söyler:

Burada söylemek istediğimiz husus bu ikinci grup çalışmaların divanı incelenen şahsin edebi şahsiyetinin edebiyat tarih(ler)imizde yer buluşlarına katkıda bulunmaktan ziyade Divan edebiyatı metinlerinin anlaşllmasına katkıları olduğudur. Hatta bu eserlerin kurgu ve metotlarının bir senteze gidilmesine müsait olmadı̆̆ııı da söyleyebiliriz (Saraç, 1999, 215).

Sözü edilen yazıda, Harun Tolasa'nın Ahmet Paşa'nın Şiir Dünyası adlı çalışmasına da değinilerek bunun Çavuşoğlu'nun eserinin çerçevesinde kaldığ 1 ve aynı yöntemi benimsediği vurgulanır. Bu konuda ikinci yazıyı, Türkiye'de Eski Türk Edebiyatı kürsülerinde yapılan metin tahlili çalışmalarının bibliyografik ve istatistiksel verilerinden yola çıkarak "resmini çekmeye çalışan" İsmail Güleç kaleme alır (Güleç, 2007, 1-27). Yazar, adı geçen makalesinde Ömer Ferid Kam'ın (1864-1944) Âsâr-ı Edebiye Tedkîkâtı ile ilk müstakil divan tahlili çalışması olan Tarlan'ın Şeyhî Divânı'nı Tetkîk'inden başlayarak bu zamana kadar yapılan divan tahlili çalışmalarını incelemiştir. Bunlardaki yöntemleri örneklendirerek karşılaştıran Güleç, özellikle Cemal Kurnaz'ın Hayalî Bey Divanı (Tahlil)'inin diğer tahlillere göre daha ayrıntılı ve sistematik olduğunu, ayrıca bu çalışmanın Ahmet Paşa, Necatî, Hayalî Bey ve Nevî divanları üzerine yapılmış divan tahlillerindeki teşbih ve mecazları istatistiksel bilgilerle karşılaştırma imkânı sağlayarak benzerlerinden ayrıldığını belirtmiştir. İsmail Güleç yaptığı değerlendirmede, otuz dokuz tezde bir divanın tamamı üzerinde çalışıldığını, divanların farklı yönleri üzerine yapılan çalışmaların ise yüz elli civarında olduğunu tespit etmiştir. Ayrıca yazıda, divan tahlili çalışmalarının bibliyografyaları, bunların yürütüldüğü üniversiteler, çalışmaları yürüten danışman hocalar üzerinde durularak bir takım sonuçlara gidilmiş ve şunlar söylenmiştir:

Doktora tezleri divan tahlilinin ilk örneklerinden olan Mehmet Çavuşoğlu
ve Cemal Kurnaz'ın ögrencilerine bu konuda çalışma yaptırmamaları
bize oldukça manidar gelmektedir. Aynı şekilde Ankara Üniversitesi ho-
calarından Hasibe Mazıŏlu, Meserret Diriöz, Cem Dilçin, İsmail Ünver'in
de bu konuda çalışma yaptırmamaları dikkatimizi çekmektedir. Bunların
yanında Hüseyin Ayan, Abdülkerim Abdülkadiroğlu, Coşkun Ak, Günay
Kut, Abdülkadir Karahan, Tunca Kortantamer ve Namık Açıgözz gibi
sahanın önemli hocalarının bu konuyla ilgilenmemelerinin nedeni ayrı
bir çalış̧a konusu olacak kadar ilginç gözükmektedir (Güleç, 2007, 1-27).

İ. Güleç, Harun Tolasa'nın Ahmet Paşa'nın Şiir Dünyası'nı ise yanlızca bu eserin ilk divan tahlillerinden biri olması yönüyle değerlendirir. Divan tahlilleri konusunda bir diğer makaleyi Üzeyir Aslan yazar (Aslan, 2007, 77-94). Adı geçen yazısında Aslan, tahlil kavramını ve ilk tahlil örneklerini inceleyerek şimdiye kadar yapılan bu tür çalışmaların bibliyografyasını verir. Ü. Aslan, bu konuyla ilgili diğer yazılardan farklı olarak Çavuşoğlu ve Tolasa'nın tahlil çalışmalarındaki sistematik indekslere değinerek bunların önemi üzerinde durur (Aslan, 2007, 82). Divan tahlilleriyle ilgili sözü edilen üç yazıda da Harun Tolasa'nın Ahmet Paşa'nın Şiir 
Dünyası adlı eserinin Tarlan'dan sonra yapılan ilk tahlil çalışmalarından biri olması yönüyle değerlendirildiği görülür.

Harun Tolasa'nın Osmanlı Edebiyatı araştırmalarına asıl özgün katkısı, on altıncı yüzyılın en önemli üç şairler tezkiresini "tezkirecilerin kendilerine özgü dikkat ve ifade özellikleri"ni gözeterek bilimsel bir anlayışla ele alıp incelediği Sehî, Latifì ve Aş̧ı Çelebi Tezkirelerine Göre 16. yüzyılda Edebiyat Araştırma ve Eleştirisi I adlı kitabıdır (Araştırmacının benzeri yazıları için bkz. Tolasa, 1980, 199-230; 1982, 15-46). H. Tolasa'nın 1970 yılında ihtisas için gittiği Amerika'da edindiği bilgi ve deneyimleri de değerlendirdiği bu özgün doçentlik takdim tezi, 1983 yılında kitap olarak basılmıştır. H. Tolasa sözü edilen kitabın önsözünde bu çalışmadaki amaçlarını şöyle sıralar:

1) Bir tezkirenin gerçek mahiyeti ve muhtevası

2) Tezkire yazarının (ve dolayısıyla çağının) edebî anlayış ve değer sistemi

3) Tezkirecinin edebî araştırma-eleştiri metod ve üslûbu

4) Çağın edebiyat dünyası (Tolasa, 2002, XI)

Her çağın edebî bir eleştirisi olduğu ve "kendilerini doğrudan birer edebî eleştiri eseri olarak görmesek bile" tezkirelerin "bu devrin edebî eleştirisini en çok temsil eden eserler" olduğu düşüncesinden hareket eden Tolasa, çalışmasını iki genel başlık üzerine kurar: I. Biyografik Bilgi ve Değerlendirmeler; II. Edebî Kişilikle İlgili Bilgi ve Değerlendirmeler. Edebî kişilikle ilgili değerlendirmeleri Tolasa, üç ana etken üzerine oturtur. Bunlar; yaratılış, şairin edebî kültürü ve çevre (okuyucu çevresi)' dir. İkinci bölüm yani tezkirecilerin şairlerin edebî kişiliğiyle ilgili bilgi ve değerlendirmeleri yaparken kullandıkları edebî eleştiri terimleri, Tolasa'nın özellikle dikkat çekmek istediği ve yoğunlaştı̆̆ 1 bir bölümdür (Harun Tolasa'ya göre bu terimler, tezkireciler ve şairler tarafından gelişigüzel bir biçimde değil bilinçli ve tutarlı bir biçimde kullanılmaktadır. Bu konuya dikkat çeken başka incelemeler için bkz. Açıkgöz 2000, 149-160; Çapan, 2002, 11-48; Kılıç, 2003, 110-115; Dilçin, 2009, 123).

Kitabın ikinci bölümü, ilkin "yaratılış bakımından şair”i ele alan değerlendirmeleri içerir. Şairin yaratış özellikleri tab', selîka, kabiliyet terimleriyle; şairin doğal sanat kudreti ise hoş, hûb, bed; latîf (lutf, letafet); selîm, nazik, zarîf; şûh, çalak; pâk, küşâde; pâk, nazif; bülend, âlî; halavet, vekkâd, has, sâde; derrâk, cevherdâr, pür-güher gibi niteleyici terimlerle değerlendirilirler. Bu değerlendirmelerde Tolasa, şu açıklamayı yapma gereği duyar:

Aşağılda tek tek gözden geçireceğimiz bütün bu tavsif ve takdirler, gerçi bir şairin doğal sanat gücü üzerine, sanata dayall, somut, ayrintılara inen, özel durumlarl yakalayan ve bunu belgeleyen bir eleştiri olmaktan çoğunlukla uzak kalırlar, ama bir yandan şairin bu yönü üzerine genel bir fikir vermekten, diğer yandan da, sanatta doğal güç üzerine çă̆ının düşünce, anlayış ve hassasiyetini yansitmaktan geri kalmazlar (Tolasa, 2002, 202).

Bunun yanında, şairin yaratılış hali ve özelliklerini imleyen icad, ibda, ihtira terimlerinin tezkire dilinde "şairliğin can damarı"nı oluşturmaları, "yaratma, yeni şeyler ortaya koyabilme, sanat eserine kişiliğinin damgasını vurabilme" anlamında taşıdıklanı önem büyüktür. Yine aynı paralelde şairin sanat kişiliği için önemli bir değer olan tasarruf, bir orjinallik göstergesi, alışılmışın dışına çıkıp ezber bozmayı nitelemekte; bedîhe-gûu, fevrîlik terimleri ise düşünmeksizin anında söyleyebilme becerisini, bir takdiri nitelemektedir. Öte yandan tezkire dilinde verimlilik, bolluk ve gürlük gibi anlam alanlarını ifade eden cevdet-i tab' terimiyle birlikte yine aynı yolda söylenen hiddet, sürat, tizlik terimleriyle de anında ve çabuk yazma becerisine gönderme yapılır. Yine bu çerçevede şairin sanatındaki incelik ve özeni anlatan dikkat, müdekkik; şairin “değerliyi değersizden ayırt edebilme gücü”nü vurgulayan nekkâd, güher-senc, 
vezn-i tab', sühân-ârâ terimleri de tezkirecilerin çok önemsedikleri şairin sanat gücünü ifade eden şiir eleştiri terimlerindendir. Bütün bunları adı geçen eserinde, titiz ve toplu bir biçimde ortaya koyan ilk araştırmacı Harun Tolasa olmuştur.

Öte yandan kitabın sözü edilegelen ikinci bölümünde "eserin yapısına ait unsurlar" bölümündeki sanat, hayal, mana ve fikr, elfâz ve edâ terimleri de büyük önem taşımaktadır. H. Tolasa, bunların tezkire dilindeki karşılıklarını somutlaştırmak için Âşık Çelebi’nin Bakî değerlendirmesini örnek olarak verir: "Şiiri muhkem ve üstüvâr, hemvâr u pürkâr, rengîn, çâşnîdâr, elfâzı selîs, ma'nâsı nefîs, nazmı pâk ve mefhûmı sûznâk...” (Tolasa, 2002, 357). Araştırmacı, eserin yapısına ait bu eleştiri terimlerinin "bugünkünden az çok farkll, çağının edebi-estetik bilgi, kültür, düşünce ve anlaylşlarından kaynaklanan kendine özgü bir anlam taşıdıkları" nı kesin bir dille vurgular. Terimlerden, kavramlardan, deyim veya tabirlerden oluşan bu "tezkire dili", Tolasa'nın sözü edilen çalışmasıyla bilimsel bir kimliğe kavuşmuştur. $\mathrm{Bu}$ eser üzerine tanıtma yazan Tunca Kortantamer, bu incelemeyi hem yeni bakış açıları getirmesi hem de tezkirelerle ilgili ayrıntılı incelemeye gitmeyen basmakalıp yermelerin gözden geçirilip düzeltilmesi bağlamında önemli bir görevi yerine getirmesi yönleriyle değerlendirir. Tolasa'nın eserin tezkireci tarafından edebi bir eser olarak değerlendirilmesi ile ilgili çalışması (ikinci cild olarak planlanan) hakkında şunları söyler:

...H. Tolasa'nın kendisinin de çok önemsediği ve incelemenin ikinci cildi olarak hazırlamakta olduğu doğrudan eserin tezkireci tarafindan bir edebiyat eseri olarak değerlendirmesine, yani edebiyat eleştirisine yönelik çalı̧̧manın tamamlanmamış olması araştırma dünyası için üzücü̈ür. Merhumun tarama işlerini bitirdiğini, fişlerini düzenlediğini, konuyla ilgili hazırlıklarının tamam olduğunu kendisinden sık sık duymuşs olduğumuz ve bu konuda zaman zaman kendisiyle konuşmuş bulunduğumuz için söz konusu malzemeden yararlanılmast gerektiğini de hatırlatmak isteriz (Kortantamer, 1983, 206).

Yine aynı çerçevede Cem Dilçin, gazellerin niteliklerini belirtmek için tezkireciler tarafından kullanılan sıfatların şairlerin sanatlarına 1şık tuttuğu gibi üsluplarına ilişkin de bazı ipuçları verdiğini belirterek Harun Tolasa'nın sözü edilen kitabında geçen sıfatları yazısında listeledikten sonra şunları söyler:

Tezkirecilerin divan şairleri için kullandıkları bu türlü bazı sıfatlardan neyi kastettikleri, ne o şairler üzerine çalışanlar ne de Tanzimat sonrası edebiyat tarihi yazarlarınca ayrıntıl, yeterli ve gerektiği biçimde incelenmiş de değildir. Söz konusu yazarlar tarafindan ayrıca, tezkirecilerin koydukları ölçütler doğrultusunda divanlardan yaptıkları seçme beyitler üzerinde de bu yönde karşılaştırmalı bir çalışma yapılmamıştır. Oysa tezkirecilerin kendi çağlarında, yaşadıkları toplumsal ortam içerisinde, tarihselleşmeden ve güncel niteliğini yitirmeden divanlardan seçtikleri o örneklerin, günümüzün edebiyat anlayışına göre seçilmiş örneklerden çok daha nesnel olarak döneminin "yazınsal değerler"ini yansıttı̆̆ konusunda hiç kuşku yoktur. Durum böyle olmakla birlikte, tezkirecilerin bu yolda yaptıkları seçkiler ne yazık ki bu alanda çalışanlar tarafindan son dönemlere kadar pek fazla dikkate alınmamıs, buna ek olarak günümüzün edebiyat anlaylşıly geriye doğru bakılarak divan şiiri ve şairleri değerlendirilmiş, bunun sonucunda da gerçeğe aykırı ya da yanlış birtakım yargılara varılmıştır (Dilçin, 2007, 123). 
Bütün bu bakış açılarından anlaşıldığı üzere Harun Tolasa'nın "Sehi, Latifî, Âşık Çelebi Tezkirelerine Göre 16. Yüzyılda Edebiyat Araştırma ve Eleştirisi I" adlı kitabı, özellikle tezkirelerdeki şair ve şiir için kullanılan terimlerin belli bir sınıflandırma ile derli toplu verilmesi bakımından zamanı için önemli bir araştırma alanı açmış, böylelikle özgün bir çalışma olarak model alınagelmiştir. Sözü edilen bu kitabı örnek alan ilk çalışmayı, on sekizinci yüzyıl tezkireleri üzerine Pervin Çapan yapmıştır (Çapan, 1993). P. Çapan, ayrıca diğer yazılarında Safayî tezkiresi ve Zatî divanı örneğinde eleştiri terimleri ve bir üslup öğesi olarak örnek verme işlemini önceleyerek bunların "tezkire dili"ne katkılarını ele alan yeni bakış açıları sunmuştur (Çapan, 2002, 11-48; 2009, 99-101). Yazar, "Bir Üslup Unsuru Olarak Safayi Tezkiresinde Örnek Verme Işlemi" adlı makalesini, Tolasa'nın "Şair Tezkirelerinde Örnek Verme Işslemi" adlı makalesindeki yöntem çerçevesinde incelemiş ve değerlendirmiştir. Yine bu konuda bir diğer önemli çalışmayı Filiz Kılıç, on yedinci yüzyıl tezkirelerini inceleyerek gerçekleştirmiştir. F. Kılıç, kitabının önsözünde bu konuyu şöyle değerlendirmektedir:
Çalışmanın sistematiği, merhum Harun Tolasa'nın "Sehî, Latifì ve Âşık Çelebi Tezkirelerine Göre 16. yüzyllda Edebiyat Araştırma ve Eleştirisi I" adlı eseri ile Pervin Çapan'in hazırladı̆̆ "18. yüzyll Tezkirelerinde Edebiyat Araştırma ve Tenkidi" adl doktora tezindeki metottan fayda- lanılarak oluşturulmuştur. 17. yüzyll tezkireleri hacim ve muhteva açısından 16. yüzyll ve 18. yüzyll tezkirelerinden farklıllk gösterdiği ve onlara göre muhtasar olduğu için bizim planımız bu çalışmaların planıyla tam olarak örtüşmemektedir. Örneklenen metinler aracılı̆̆ıyla yapılan takdim ve tavsiflerde, söz konusu eserlerle birleşen yorum ve değerlendirmeler yeri geldikçe belirtilmiş, zaman zaman tablolarla da mukayese yoluna gidilmiştir (Kılıç, 1998, X).

Harun Tolasa'nın açtığ Tenkit [Şairin Şaire Bakışı]”" adlı kitapla Menderes Coşkun yapmıştır (Coşkun, 2007). Araştırmac1, tezkireler yerine mesnevi ve divanlarda Osmanlı şairlerinin birbirleri ile ilgili övgü, eleştiri ve değerlendirmelerini ele aldığ önemli çalışmasında, şiir ve şair ile ilgili eleştiri örneklerinin yanında şairlerin birbirleri hakkındaki manzum değerlendirmelerine de yer vermiştir (Yazarın adı geçen kitabındaki bazı yazılar, daha önce aşağıdaki dergilerde yayımlanmıştır. Bkz. Coşkun, 2003, 313-368; 2005a, 87-128; 2005b, 163-174). Yine bu bağlamda önemli çalışmalardan biri de Yusuf Çetindağ'ın "Şiir ve Tenkit [Türk, Iran ve Arap Tezkirelerinde] adlı kitabıdır. Yazar, sözü edilen çalışmasında, genel anlamda tezkireleri, tezkirecilerin şair değerlendirme yöntemlerini, biyografik bilgi geleneğini bütün yönleriyle irdelemiştir. Hiç şüphesiz bütün bunlar içinde çalışmanın en can alıcı yönü, yazarın Arap, Fars ve Türk tezkirecilerinin tercih ettiği eleştiri terimlerini, büyük bir titizlikle karşılaştırmalı olarak incelemesidir. Ayrıca Çetindağ, sözü edilen eleştiri terimlerinin tezkirelerde yer alış sıklığını da tablolar halinde göstererek çok önemli katkılar sunmuştur (Çetindağ, 2010, 323-331). Tolasa'nın Osmanlı şiiri alanında önemli bir çalışma sahası oluşturup model alınan bu kitabı, görüldüğü üzere farklı ve özgün çalışmaların ortaya konmasında yol açıcı bir eser olmuştur. Harun Tolasa'nın Osmanlı edebiyatına özellikle tezkire çalışmalarındaki yeni bakış açıları getiren eserleri, Haluk İpekten (1926-1992) ve Mustafa İsen gibi bu alandaki öncü isimlerin çalışmaları ile birlikte ele alındığında bütünleyici bir işlevi yerine getirmiştir. Yine bu araştırmaların sonra gelen akademisyenler tarafından sürdürülmesi de büyük bir çalışma alanının ortaya çıkmasına vesile olmuştur.

Harun Tolasa'nın bu alana önemli katkılarından biri de ilk olarak Osmanlı Edebiyatı'ndaki divan önsözlerini (dibace) inceleme konusu olarak ele almasıdır. "Klasik Edebiyatımızda Divan Önsöz (Dibace)leri; Lami'̂̀ Divanı Önsözü ve (buna göre) Divan Şiiri Sanat Görüşü” adlı 
makalesinde, divan önsözlerinin önemi hakkında şunları söyler:

Klasik Edebiyatımızın el değmemiş veya gerektiği gibi araştırılmamış konularından birisi de, bu edebiyatın dayandığı düşünceleri, anlayışları, ilke ve kuralları ortaya koyan, yani onun kuramsal yapısını içeren kitaplar, risaleler veya önsöz (dibace) vb. yazılar olmaktadır. O döneme ait bazı şairlerimizin divanlarının başlarında görülen önsöz (dibaceler) de bu tür eser ya da yazılardan okuyup bildiğimiz kadarınca, şimdiye değin müstakil bir araştırmaya konu olmamıştır (Tolasa, 1999, 229).

Kırka yakın önsöz metnini tespit eden Tolasa, bu yazısında sadece Lamiî Divanı'nın önsözünü ele almış ve gerektikçe diğer önsöz metinlerinden yararlanma yoluna gitmiştir. Ve yazısında, bunları metin olarak yayımlama düşüncesinin de olduğunu belirtmiştir. Ancak Tolasa'nın sözünü ettiği divan dibacelerinin yayıma hazırlanması, bu makalenin yazım tarihinden on bir yıl sonra Tahir Üzgör tarafından gerçekleştirilecektir (Üzgör, 1990).

Harun Tolasa'nın akademik çalışmaları içinde sözü edilmesi gereken bir diğer verimi, otobiyografik bir metin olan Kendi Kalemiyle Temeşvarlı Osman A ̆ga [Bir Osmanlı Türk Sipahisi ve Esirlik Hayatı] adlı eseridir. On yedinci yüzyılın ikinci, on sekizinci yüzyılın ilk yarılarında yaşamış Temeşvarlı bir Rumeli Türk'ünün sınır boyu süvarisi olarak görev yaparken 1687'de Lipova kalesinde Avusturyalılara esir düşmesi ve on iki yıllık esirlik hayatının anlatıldığı bu çalışmayı Tolasa, 1963 yılında Prof. Fahir İz'in danışmanlığında fakülte bitirme tezi olarak hazırlamıştır. Bu eser, aynı zamanda Dr. Richard F. Kreutel ve Otto Spies tarafından da Almancaya çevrilerek yayımlanır. Daha sonra, 1961 ve 1962 yıllarında M. Şevki Yazman tarafından Türkçe'ye çevrilir. 1971'de ise Esat Mermi tarafından Milliyet yayınlarından çıkar. H. Tolasa, önsözde eser üzerinde bu kadar yayın olduğu halde niçin bu konunun tekrar ele alındığını şöyle açıklar:

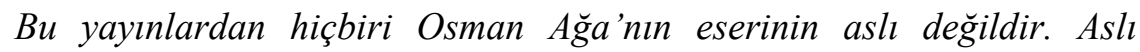
olmadı̆̆ gibi, onun kendi dönemi Türkçesinden günümüz Türkçesine yapılmış bir aktarması ve sadeleştirmesi de değildir. İçinde bu konuda herhangi bir açıklama bulunmamakla birlikte, Milliyet yayını, daha önce de söylediğimiz gibi, Almanca tercümenin bütünüyle ve aynen tekrar Türkçeye tercümesinden ibarettir. M. Şevket Yazman'ın yayını ise, yine daha önce işaret ettiğimiz gibi, Almanca tercümenin 1954 yll yayınına dayanmaktadır. Ancak bu dayanmanin ne ölçüde olduğu kesin söylenemez. Çünkü hikaye çok serbest bir aktarma içerisinde ve dikkati çekecek ölçüde özetlenererek verilir. Her iki yayının da durumu muhakkak ki bizim bu çalışmamızla yapılacak kısa bir karşılaştırmadan sonra daha iyi anlaşllacak ve Osman Ăga'nın hayat hikayesine el atmamızın nedeni böylece kendiliğinden ortaya çıkacaktır (Tolasa, 2004, 10).

H. Tolasa, sözü edilen yayınlarla kendi çalışmasını karşılaştırarak aralarındaki farkları ortaya koyar. Yazar, giriş bölümünde Osmanlı edebiyatında otobiyografi, otobiyografi biyografi ilişkisi, temel otobiyografik metinleri irdeleyerek üzerinde çalıştığı metnin özgünlüğünü okuyucuya aktarmayı hedefler. Kitabın giriş bölümü, Osmanlı edebiyatında otobiyografi ile ilgili önemli referanslardan biridir. Onun sözü edilen giriş bölümü ile birlikte, Cemal Kafadar'ın dört 'deneme'sinin bir araya getirilmesiyle oluşturulan Kim Varmış Biz Burada Yoğ İken [Dört Osmanll: Yeniçeri, Tüccar, Derviş ve Hatun] adlı kitabının ikinci bölümünü oluşturan "Ben ve Başkaları [On Yedinci Yüzyll İstanbul'unda Bir Dervişin Güncesi ve Osmanlı Edebiyatında Birinci A ̆gıdan Anlatılar]" adlı yazısı, bu konuda çalışacaklar için çok önemli bir diğer kaynaktır (Kafadar, 2009). C. Kafadar, sözü edilen yazısında Tolasa'nın bu çalışmasından 
"modern Türkçe uyarlama" olarak söz açar. Bu metnin, Osmanlı edebiyatında birinci ağızdan anlatıya dayanan eserler içinde önemli bir yer tuttuğunu belirtir.

Bu yazıyla daha çok Tolasa'nın genel çalışma alanları, özellikle üzerinde israrla durduğu konular, bunların daha sonraki araştırmacılar tarafından algılanış biçimleri ve eserleri hakkındaki eleştiriler üzerinde yoğunlaşılmıştır. Harun Tolasa, derin bilgisi, titizliği ve model alınan eserleriyle Osmanlı edebiyatı çalışmalarında çok önemli bir isim olagelmiştir.

\section{KAYNAKÇA}

Açıkgöz, N. (2000). "Klasik Türk Şiiri Tenkid Terminolojisi ve 'Âbdâr' Örneği”. Türk Kültürü Incelemeleri Dergisi, 2, 149-160.

Aslan, Ü. (2007). "Klasik Türk Edebiyatında Tahlil Çalışmaları". Türkiye Araştırmaları Literatür Dergisi, 10, 77-94.

Çavuşoğlu, M. (2001). Necati Bey Divanı'nın Tahlili. İstanbul: Kitabevi Yayınları.

Coşkun, M. (2003). "Mesnevilerde Klasik Şairlerle İlgili Değerlendirmeler". Journal of Turkish Studies [Türklük Bilgisi Araştırmaları] Kaf Dağının Ötesine Varmak, Festscrift in Honor of Günay Kut. 27 (I), 313-368.

Coşkun, M. (2005a). "Divan Şairlerinin Birbirleriyle İlgili Manzum Değerlendirmeleri”. Türk Kültürü Incelemeleri Dergisi, 13, 87-128.

Coşkun, M. (2005b). "Türk Divan Şairlerinin Birbirlerini Değerlendirme Tarzları". Osmanlı Araştırmaları, XXVI, 163-174.

Coşkun, M. (2007). Klasik Türk Şiirinde Edebî Tenkit [Şairin Şaire Bakışı]. Ankara: Akçağ Yayınları.

Çapan, P. (1993). 18. yy. Tezkirelerinde Edebiyat Araştırma ve Tenkidi. Basılmamış Doktora Tezi. Fırat Üniversitesi Sosyal Bilimler Enstitüsü, Elazı̆̆.

Çapan, P. (2002). "Zâtî Divanında Edebî Tenkid ve Değerlendirmeler". Muğla Üniversitesi Sosyal Bilimler Enstitüsü Dergisi (10. Yı1 Özel Sayıs1), 8, 11-48.

Çapan, P. (2009). "Bir Üslup Unsuru Olarak Safayî Tezkiresi’nde Örnek Verme İșlemi”. Uluslararası Türk Dili ve Edebiyatı Kongresi, 27-28 Ağustos 2007, Bildiriler [Türk Edebiyatında Üslup Arayışları II]. İstanbul: İstanbul Kültür Üniversitesi Yayınları.

Çetindağ, Y. (2010). Şiir ve Tenkit [Türk, İran ve Arap Tezkirelerinde]. İstanbul: Kitabevi Yayınları.

Dilçin, C. (2009). "Divan Şiirine Stilistik Yaklaşım". Uluslararası Türk Dili ve Edebiyatı Kongresi, $27-$ 28 A ̈gustos 2007, Bildiriler [Türk Edebiyatında Üslup Araylşları II]. İstanbul: İstanbul Kültür Üniversitesi Yayınları.

Güleç, İ. (2007). "Türkiye Üniversiteleri Türk Dili ve Edebiyatı Bölümlerinde Divan Tahlili Üzerine Yapılan Çalışmalar”. Journal of Turkish Studies [Türklük Bilgisi Araştırmaları], 31, II, 1-27.

Kafadar, C. (2009). Kim Varmış Biz Burada Yoğ İken [Dört Osmanlı: Yeniçeri, Tüccar, Derviş ve Hatun]. İstanbul: Metis Yayınları.

Kılıç, F. (1998). XVII. Yüzyll Tezkirelerinde Şair ve Eser Üzerine Değerlendirmeler. Ankara: Akçağ Yayınları.

Kılıç, F. (2003). “Tezkirelerde Şiirin Âhengini Belirten Kelimeler Üzerine”. Milli Folklor, 60, 110-115.

Kortantamer, T. (1983). "Prof. Dr. Harun Tolasa: Sehi, Latifî, Âşık Çelebi Tezkirelerine Göre 16. Yüzyılda Edebiyat Araştırma ve Eleştirisi I". Ege Üniversitesi Türk Dili ve Edebiyatı Araştırmaları Dergisi (Prof. Dr. Harun Tolasa Özel Sayıs1). II, 205-207.

Kortantamer, T. (2004). Eski Türk Edebiyatı Makaleler. Haz. Şerife Yağc1, \& Fatih Ülken. Ankara: Kültür Bakanlığı Yayınları.

Saraç, M., \& Yekta A. (1999). "Divan Tahlilleri Üzerine”. İlmî Araştırmalar. 8, 209-219.

Tolasa, H. (1980). "Şair Tezkirelerinde Örnek Verme İşlemi". Ege Üniversitesi Sosyal Bilimler Fakültesi Dergisi, $I, 199-230$.

Tolasa, H. (1982). 'Divan Şairlerinin Kendi Şiirleri Üzerine Düşünce ve Değerlendirmeleri”. Ege Üniversitesi 
Edebiyat Fakültesi Türk Dili ve Edebiyatı Araştırma Dergisi, 1, 15-46.

Tolasa, H. (1999). "Klasik Edebiyatımızda Divan Önsöz (Dibace)leri; Lami’î Divanı Önsözü ve (buna göre) Divan Şiiri Sanat Görüşü”. Osmanlı Divan Şiiri Üzerine Metinler. Haz. Mehmet Kalpaklı. İstanbul:Yapı Kredi Yayınları.

Tolasa, H. (2001). Ahmet Paşa'nın Şiir Dünyası. Ankara: Akçağ Yayınları.

Tolasa, H. (2002). Sehî, Latifî ve Âşık Çelebi Tezkirelerine Göre 16. Yüzyılda Edebiyat Araştırma ve Eleştirisi. Ankara: Akçağ Yayınları.

Tolasa, H. (2004). Kendi Kalemiyle Temeşvarlı Osman Ağa [Bir Osmanlı Türk Sipahisi ve Esirlik Hayatı]. Ankara: Akçă̆ Yayınları.

Üzgör, T. (1990). Türkçe Divan Dibaceleri. İstanbul: Kültür Bakanlığı Yayınları. 